Chapter 5

\title{
Electrochemical Transformation of White Phosphorus as a Way to Compounds With Phosphorus-Hydrogen and Phosphorus-Carbon Bonds
}

\author{
Yu. G. Budnikova and S. A. Krasnov \\ Additional information is available at the end of the chapter \\ http://dx.doi.org/10.5772/53886
}

\section{Introduction}

Organophosphorus compounds (OPC) have gained huge importance in modern manufacturing of bulk and fine chemicals and, apart the classic applications as fertilizers, detergents and pesticides, they represent the basic compounds for the development of intriguing materials for micro- and optoelectronics, coherent and nonlinear optics, selective extractors for rare-earths and transuranic elements, additives for plastic materials (flame retardants, plasticizers, softeners, etc.), additives to lubricant oils and liquid fuels, flotation agents, emulsifiers, etc. More recent OPC applications have come out in the field of biologically active compounds for medicine (chemotherapics, antiviral agents, biocompatible materials for bone and dental reparations, etc.) and in agrochemistry.

The interest in the direct synthesis of OPC from elemental phosphorus, escaping the traditional stages of its chlorination, stems from the increasing needs to reorient the chemical technology towards the strategic target of combining increased ecological safety with lowwaste production. In this context, a replacement of the current process for the preparation of basic OPC using phosphorus chloride and oxychloride is of paramount importance. The existing processes are environmentally dangerous, energy-consuming and utterly remote from the concepts marking out green chemistry technological processes. The formation of hydrogen chloride accounting, by mass, for three quarters of the used $\mathrm{PCl}_{3}$ is the key disadvantage in the $\mathrm{P}_{4}$ chlorination process.

Until the middle of eighties, electrochemical reactions played a minor role in industrial synthetic chemistry in spite the use of electrochemistry had a long tradition in organic chemistry, as shown for example by the Kolbe reaction to produce symmetrical hydrocarbon 
dimers by electrochemical oxidative decarboxylation of carboxylic acid salts [1,2]. During the sixties electrochemical methods were used to produce tetraethyl lead and adiponitrile, but such applications in large commodities manufacturing may be considered rather atypical. In spite of the shortage of industrial applications, electrochemical reactions have a number of advantages, such as the generally mild and controllable working conditions and the easy control of process rate. Additionally, the selectivity of the process may be easily controlled by a judicious choice of parameters, such as the density current and the potential [3-6].

In this short report we intend reviewing the use of electrochemical methods to generate OPC from the direct transformation of elemental phosphorus. Particular attention will be paid to illustrate the electrocatalytic processes where the use of a metal catalyst would allow for the highly desirable functionalization of white phosphorus. Homogeneous reactions catalyzed by transition metals proceed through reaction cycles involving the metal in different oxidation states readily detectable by a variety of electrochemical methods (voltammetry, amperometry, chronoamperometry, etc.) [3-7].

\section{Experimental}

Preparative electrolyses were performed using the direct current source B5-49 in thermostatically controlled cylindrical divided electrolyser (a three-electrode cell) with $40 \mathrm{~cm}^{3}$ volume. Silver $\mathrm{Ag} / \mathrm{AgNO}_{3}$ electrode $(10 \mathrm{mM}$ solution in $\mathrm{MeCN})$ served as a reference one. Lead cylinder with surface area of $20 \mathrm{~cm}^{2}$ was used as a cathode. During electrolysis the electrolyte was stirred with a magnetic stirrer. The aqueous acetate buffer was used as catholyte. The saturated potassium acetate aqueous solution was used as anolyte, and the ceramic membrane divided cathodic and anodic spaces. Platinum wire served as an anode. All manipulations and reactions were carried out under dry Ar atmosphere.

The images of the films were obtained on a HITACHI TM-1000 scanning electron microscope.

NMR-spectroscopy of 1H, 31P, IR-spectroscopy, chromatographic analysis, elemental analysis were used to establish the structure and yields of electrosynthesis products. The obtained physical characteristics of the products correspond to the data available in literature.

The NMR 31P spectra were recorded using CXP-100 Brucker spectrometer (85\% H3PO4 as an external standard). The NMR $1 \mathrm{H}$ spectra were recorded using MSL-400 Brucker spectrometer.

Alkenes were used without any purification (Acros).

\subsection{Electrochemical measurements}

A cyclic voltammetry (CVA) was carried out with potentiostat E2P Epsilon (BASi, USA) consisting of detector, personal computer Dell Optiplex 320 with software EpsilonEC-USB- 
V200, and electrochemical cell C3 having three-electrode scheme. A linear potential scanning speed was $100 \mathrm{mV} / \mathrm{s}$. Stationary glassy carbon electrode $(\mathrm{d}=3.0 \mathrm{~mm})$, platinum electrode $(\mathrm{d}=1.5 \mathrm{~mm})$, and DSA (Dimensionally Stable Anode) electrode $(\mathrm{d}=1.0 \mathrm{~mm}$ ) were used as working electrodes. Saturated calomel electrode (SCE) was used as reference electrode in voltammetric measurements. Platinum wire $(\mathrm{d}=0.5 \mathrm{~mm})$ was used as auxiliary electrode. Tetrabutylammonium tetrafluorborate with concentration $0.1 \mathrm{M}$ was used as a background salt in voltammetric studies. The method of cyclic voltammetry was used to evaluate of the reduction potentials of alkenes. The tetrabutylammonium tetrafluoroborate $\left(\mathrm{Bu}_{4} \mathrm{NBF}_{4}\right)(0.1 \mathrm{M})$ solution in dymethylformamide (DMF) served as electrolyte. The lead electrode $\left(S=3.14 \mathrm{~mm}^{2}\right)$ was used as the working electrode. Saturated calomel electrode served as a reference one, Pt wire being the auxiliary electrode.

Electron spin resonance (ESR) measurements were carried out using the program-apparatus complex [8] mounted on the basis of an analog-electrochemical setup with a PI-50-1 potentiostat, a Pr-8 programmer, an X-range ESR spectrometer (Radiopan), and E14-440 analogto-digital and digital-to-analog converter (L-Card), and a computer.

The WinSim 0.96 program (NIEHS) was used for ESR spectra processing.

\subsection{Preparation of solutions}

Benzene was dehydrated by distillation over sodium. $\alpha$-phenyl-N-tert-butylnitrone (1) and $\mathrm{Et}_{4} \mathrm{NBF}_{4}$ (Fluka) were used without additional purification. Acetonitrile was purified by triple distillation over $\mathrm{KMnO}_{4}$ and $\mathrm{P}_{2} \mathrm{O}_{5}$, and $\mathrm{Et}_{4} \mathrm{NBF}_{4}$ was dried in vacuo for 2 days at $100{ }^{\circ} \mathrm{C}$. Dimethylformamide was distilled, kept for $12 \mathrm{~h}$ over calcined $\mathrm{K}_{2} \mathrm{CO}_{3}$, then distilled repeatedly over $\mathrm{CaH}_{2}$, and stored over molecular sieves $3 \mathrm{~A}$ calcined at $300{ }^{\circ} \mathrm{C}$.

A solution of white phosphorus in benzene $(\sim 16 \mathrm{mM})$ was purged with helium through a capillary immersed to the bottom of the cell. The material of the working and auxiliary electrodes was platinum, and $\mathrm{Ag} / \mathrm{AgNO}_{3}(10 \mathrm{mM})$ was a reference electrode.

The saturated aqueous potassium acetate solution was prepared by addition of $56 \mathrm{~g}(1 \mathrm{M})$ $\mathrm{KOH}$ to the stirred solution of $60 \mathrm{~g}(1 \mathrm{M})$ acetic acid in $20 \mathrm{ml} \mathrm{H} \mathrm{H}_{2} \mathrm{O}$ and further solvation of the formed precipitate in minimal quantity of distilled water. The acetate buffer solution was prepared using $30 \mathrm{ml}$ acetic acid and $10 \mathrm{~g}$ of $\mathrm{KOH}$ in $30 \mathrm{ml}$ of $\mathrm{H}_{2} \mathrm{O}$.

\subsection{Electrochemical reduction of alkenes in the presence of white phosphorus}

The solution for electrolysis was prepared by mixing $16 \mathrm{mM}(0.5 \mathrm{~g})$ of white phosphorus, 48 $\mathrm{mM}$ of appropriate alkene and $20 \mathrm{ml}$ of aqueous acetic buffer solution, as supporting electrolyte, in $20 \mathrm{ml}$ of $\mathrm{H}_{2} \mathrm{O}$. White phosphorus was emulsified under argon when heated to 50 ${ }^{\circ} \mathrm{C}$ before the initiation of electrolysis. The electrolysis was carried out at $10-20 \mathrm{~mA} \mathrm{~cm}{ }^{-2}$ cathodic current density in the galvanostatic mode (about $-2.00 \mathrm{~V}$ ). The amount of electricity passed through the electrolyte was $3 e$ per atom of phosphorus. After completing the electrolysis the organic phase was isolated, washed by water and the residuary initial alkene was evaporated in vacuum. Gaseous phosphine in trace amount was directed to exhaust 
tube and captured in the adjacent vessel filled with a $1.5 \%$ aqueous solution of $\mathrm{HgCl}_{2}$. Inorganic hypophosphorus acid was product in an aqueous part of electrolyte ( $\delta \mathrm{P} 14 \mathrm{ppm}, \mathrm{J}_{\mathrm{H}-\mathrm{P}-\mathrm{H}}$ $=580 \mathrm{~Hz}$ ).

The resulting colorless oil was analyzed by NMR and IR spectroscopy.

1. $\mathrm{C}_{6} \mathrm{H}_{5}-\mathrm{CH}_{2}-\mathrm{CH}_{2}-\mathrm{PH}_{2}$. Yield: $0.69 \mathrm{~g}, 31 \%$ on phosphorus;

${ }^{31} \mathrm{P}-\mathrm{NMR}\left(\mathrm{CDCl}_{3}\right)$ : -141.5 ppm (J $\left.\mathrm{J}_{\mathrm{H}-\mathrm{P}-\mathrm{H}}=193.9 \mathrm{~Hz}\right)$; (lit.: -139.7 ppm $(198 \mathrm{~Hz})$ [9]);

IR, cm-1: 2281 (P-H); (lit.: 2280 [9]);

$\mathrm{n}_{\mathrm{d}}^{20}=1.5568$; (lit.: 1.5532 [2]; 1.5494 [10]);

b.p.: $72^{\circ} \mathrm{C}$ (7 Torr); (lit.: $46-48^{\circ} \mathrm{C}$ (1 Torr) [10]; $75^{\circ} \mathrm{C}$ (8 Torr) [11]);

Anal. Found:, \%: C, 69.90; H, 8.67; P, 21.43;

Calc. for $\mathrm{C}_{8} \mathrm{H}_{11} \mathrm{P}_{1}, \%$ : C, 69.55; $\mathrm{H}, 8.03 ; \mathrm{P}, 22.42$;

2. $\mathrm{C}_{6} \mathrm{H}_{13} \mathrm{PH}_{2}$. Yield: $0.45 \mathrm{~g}, 23 \%$ on phosphorus;

${ }^{31} \mathrm{P}-\mathrm{NMR}\left(\mathrm{CDCl}_{3}\right)$ : $-140.8 \mathrm{ppm}\left(\mathrm{J}_{\mathrm{H}-\mathrm{P}-\mathrm{H}}=190.0 \mathrm{~Hz}\right)$;

$\mathrm{IR}, \mathrm{cm}^{-1}: 2284(\mathrm{P}-\mathrm{H})$;

b.p.: $127^{\circ} \mathrm{C}$; (lit.: $127.5-128^{\circ} \mathrm{C}$ [12]);

Anal. Found:, \%: C, 60.96; H, 12.91; P, 26.13;

Calc. for $\mathrm{C}_{6} \mathrm{H}_{15} \mathrm{P}_{1}, \%$ : C, 61.02; $\mathrm{H}, 12.71 ; \mathrm{P}, 26.27$;

3. $\mathrm{C}_{6} \mathrm{H}_{5}-\mathrm{CH}\left(\mathrm{CH}_{3}\right)-\mathrm{CH}_{2}-\mathrm{PH}_{2}$. Yield: $1.12 \mathrm{~g}, 46 \%$ on phosphorus;

${ }^{31} \mathrm{P}-\mathrm{NMR}\left(\mathrm{CDCl}_{3}\right)$ : -148.7 ppm (J $\left.\mathrm{J}_{\mathrm{H}-\mathrm{P}-\mathrm{H}}=190.3 \mathrm{~Hz}\right)$; (lit.: -148.6 ppm (198 Hz) [9]);

IR, cm $\mathrm{cm}^{-1}: 2278$ (P-H); (lit.: 2280 [9]);

$\mathrm{n}_{\mathrm{d}}{ }^{20}=1.5498$; (lit.: 1.5482 [9]);

b.p.: $83-85^{\circ} \mathrm{C}$ (7 Torr); (lit.: $65-67^{\circ} \mathrm{C}$ (2 Torr) [9]);

Anal. Found:, \%: C, 70.89; H, 8.73; P, 20.38;

Calc. for $\mathrm{C}_{8} \mathrm{H}_{11} \mathrm{P}_{1}, \%$ : C, 71.04; $\mathrm{H}, 8.61 ; \mathrm{P}, 20.35$;

4. $\mathrm{CH}_{3}-\mathrm{C}(\mathrm{O})-\mathrm{O}-\mathrm{CH}_{2}-\mathrm{CH}_{2}-\mathrm{PH}_{2}$. Yield: $0.43 \mathrm{~g}, 22 \%$ on phosphorus;

${ }^{31} \mathrm{P}-\mathrm{NMR}\left(\mathrm{CDCl}_{3}\right)$ : -155.6 ppm $\left(\mathrm{J}_{\mathrm{H}-\mathrm{P}-\mathrm{H}}=195.7 \mathrm{~Hz}\right)$;

$\mathrm{IR}, \mathrm{cm}^{-1}: 2285(\mathrm{P}-\mathrm{H})$;

$\mathrm{n}_{\mathrm{d}}{ }^{20}=1.453$; (lit.: 1.462 [13]);

b.p.: $34^{\circ} \mathrm{C}$ (7 Torr); (lit.: $37-38^{\circ} \mathrm{C}$ (9-10 Torr) [13]). 


\section{Result and discussion}

\subsection{Electrode reactions of elemental phosphorus}

The electrochemical reduction of white phosphorus on a mercury dropping electrode in aprotic solvents is irreversible $\left(\mathrm{E}_{1 / 2}=-1.55 \mathrm{~V}\right.$ in $\left.\mathrm{DMF}\right)$ with the number of running electrons depending on the $\mathrm{P}_{4}$ concentration. The formation of a radical-anion likely occurs at the very beginning of the electroreduction via one-electron transfer (Sch. 1):

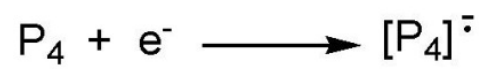

Scheme 1. The electroreduction of white phosphorus.

Rupture of one or more P-P bonds followed by formation of P-C bonds, may then take place in the presence of proton donors via fast protonation of the electrogenerated anions. The electrochemical hydrogenation of elemental phosphorus and the synthesis of phosphine derivatives were studied in detail using various types of cathodes [14, 15]. The electrochemical reduction of red phosphorus in alkali solutions has received much less attention [16]. By these methods, $\mathrm{PH}_{3}$ was synthesized in high yield using a water solution of $\mathrm{NaOH}(15-25 \%)$ and high temperature $\left(70-100^{\circ} \mathrm{C}\right)$. The yield of phosphine ranges between $60-83 \%$ at the lead cathode [16]. The application of a turbulent flow of the catholyte during the addition of a white phosphorus emulsion in a vertical electrolysis cell resulted in an improved efficiency in the electroproduction of $\mathrm{PH}_{3}$ [17].

The electrochemical oxidation of white phosphorus coated on porous conductive matrices in neutral and acidic media was applied to produce stoichiometrically both phosphoric and phosphorous acids [18]. The indirect electrochemical formation of phosphorous oxyacids from $\mathrm{P}_{4}$ took place in aqueous $\mathrm{HX}$ solutions $(X=\mathrm{Cl}, \mathrm{Br}$, I) $[19,20]$, but addition of non-aqueous solvents, such as benzene or chloroform, was sometimes necessary [19]. The oxidation of phosphorus by free halogen, previously liberated at the anode, is probably the first stage of the reaction to yield phosphorus halide derivatives, which are then hydrolysed to $\mathrm{H}_{3} \mathrm{PO}_{3}$.

The electrosynthesis of phosphorus and hypophosphorus acids was also reported from a suspension of red phosphorus in water in the presence of ethylenediamine and triethylamine [20]. The yields depended on the consumed electricity, although after ca. $9 \mathrm{~F}$ the content of phosphites and hypophosphites increased insignificantly. Nonetheless, the overall conversion to phosphorus species never exceeded $40-45 \%$ with poor selectivity in either products.

\subsection{Spin-adduct of the radical anion $P_{4} \cdot$}

The problem of the selective cleavage of the P-P bonds in a white phosphorus molecule is very important in the chemistry of phosphorus-containing compounds [21, 22]. The radical character of the cathodic reduction of white phosphorus has been assumed earlier [23]. 
However, such products of activation of $\mathrm{P}_{4}$ have not yet been detected. The purpose of the present study was to observe the primary products of cathodic reduction of a $\mathrm{P}_{4}$ molecule. To create a necessary concentration of paramagnetic species in the resonator of an ESR spectrometer, we used a special cell with the helical working electrode [24]. The method of spin traps $[25,26]$ based on the reaction of electrochemically inactive $\alpha$-phenyl- $N$-tert-butylnitrone (1), resulting in the stable nitroxyl radical (Sch. 2), was used to detect radical anion species. The stable nitroxyl radical can be identified by ESR spectroscopy.

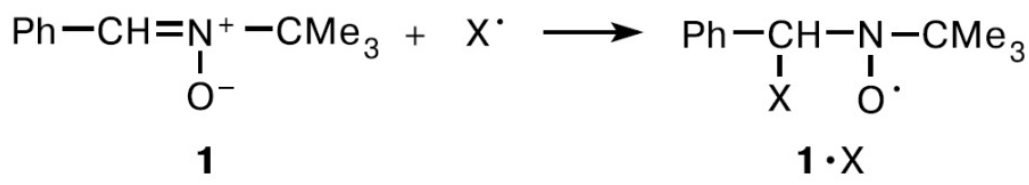

Scheme 2. Stable nitroxyl radical of a-phenyl-N-tert-butylnitrone.

The curves obtained by CVA at the Pt electrode for a solution of compound 1 in $\mathrm{MeCN}(0.01$ $\mathrm{M})$ and a solution of white phosphorus in a benzene-MeCN (1:1) mixture vs. $0.1 \mathrm{M}$ solution of $\mathrm{Et}_{4} \mathrm{NBF}_{4}$. To exclude the formation of products of phosphorus oxidation and hydrolysis, all procedures were carried out in a thoroughly dehydrated solvent. It should be mentioned that the compounds containing the mobile hydrogen atom give no pronounced reduction peaks on Pt down to potentials of the supporting electrolyte discharge. The CV curves of a solution of white phosphorus at a potential of $-1.5 \mathrm{~V}$ contain the irreversible peak corresponding to its reduction. Thus, the reduction peak close to the one-electron peak (estimated by the comparison with benzophenone used as standard) relates to the electron transfer to a white phosphorus molecule to form radical anions $\mathrm{P}_{4}{ }^{\cdot-}$.

There is a large data bank on the ESR spectra and magnetic resonance characteristics of spinadducts of compounds belonging to various classes [27]. In particular, the spin-adduct of the short-lived phosphorus-centered radical $\bullet \mathrm{PHO}_{2}^{-}$and nitrone 1 was obtained [28] by the electrochemical oxidation of hypophosphite on the nickel electrode. The following magnetic resonance parameters of the spin-adduct were detected: $a_{\mathrm{N}}=a_{\mathrm{P}}=15.91 \mathrm{G}, a_{\mathrm{H}-\mathrm{CH}}=1.99 \mathrm{G}, a_{\mathrm{H}-\mathrm{PH}}=3.21$ $\mathrm{G}, g=2.0060$. However, no spin-adducts of the P4-- radical anion were studied.

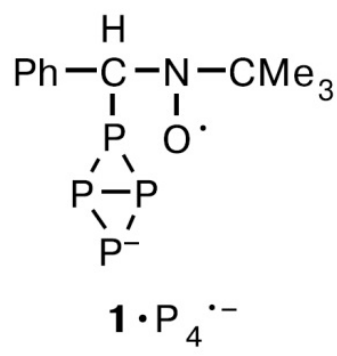

Scheme 3. Spin adduct $1 \bullet P 4^{-}$ 
The reduction peak of nitrone 1 is by $\sim 1 \mathrm{~V}$ more positive than the reduction peak of $\mathrm{P}_{4}$ $(-2.1 \mathrm{~V})$. Therefore, this trap was used for the detection of white phosphorus radical anions. The experimental ESR spectrum of the spin-adduct (Sch. 3) detected upon the reduction of white phosphorus $(\sim 16 \mathrm{mM})$ in the potentiostatic mode at a potential of $-1.5 \mathrm{~V}$ and a $1 \mathrm{M}$ solution of nitrone 1 in a benzene $-\mathrm{MeCN}$ (1:1) mixture at the Pt electrode vs. $0.1 \mathrm{M}$ solution of $\mathrm{Et}_{4} \mathrm{NBF}_{4}$ is shown in Fig. 1.

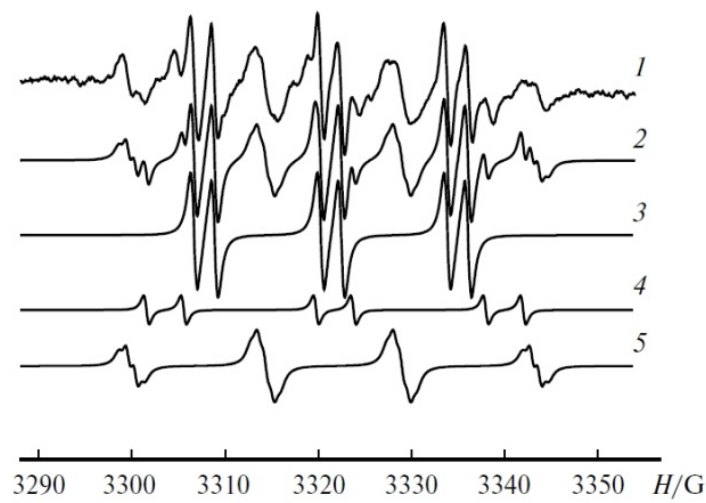

Figure 1. Experimental (1) and simulated overall (2) ESR spectra of the spin-adducts detected upon the reduction of white phosphorus and a $1 \mathrm{M}$ solution of nitrone $\mathbf{1}$ in a benzene-MeCN(1:1) mixture vs. $0.1 \mathrm{M}$ solution of Et NBF after helium purging for $10 \mathrm{~min}$ and the ESR spectra of their constituent spin-adducts: $\mathbf{1} \mathbf{1} \cdot(3), \mathbf{1} \mathbf{1}^{\prime} \cdot(4)$, and $\mathbf{1} \mathrm{P}_{4}^{-}-(5)$.

The ESR spectrum also exhibits two spin-adducts of free radicals of the spin trap 11 with the hyperfine coupling constants (HFC) $a_{\mathrm{N}}=13.59 \mathrm{G}, a_{\mathrm{H}}=2.22 \mathrm{G}$ and $a_{\mathrm{N}}=18.60 \mathrm{G}, a_{\mathrm{H}}=4.00 \mathrm{G}$ for the first and second adducts, respectively, with the ESR line widths $\delta H=0.65 \mathrm{G}$. The ESR spectrum of spin adduct $1 \bullet \mathrm{P} 4^{\bullet-}$ has the following parameters: $a_{\mathrm{N}}=14.10 \mathrm{G}, a_{\beta-\mathrm{P}}=14.6 \mathrm{G}, a_{\mathrm{H}}=$ $0.80 \mathrm{G}, a_{\gamma-\mathrm{P}}=0.78 \mathrm{G}$, and $\delta H=0.65 \mathrm{G}$. The HFC constants $a_{\beta-\mathrm{P}}$ and $a_{\gamma-\mathrm{P}}$ were attributed to the phosphorus atom in the c-position and two equivalent phosphorus atom nuclei in the $\beta$-positions to the radical center, respectively. During several first minutes after the beginning of electrolysis, the lines of the experimental spectrum begin to broaden and the pattern changes gradually, indicating the formation of polymer products. Thus, the radical anion $\mathrm{P}_{4}-$ has been fixed and identified for the first time as spin-adduct with a $\alpha$-phenyl-N-tert-butyl nitrone during electrochemical reduction of $\mathrm{P}_{4}$.

\subsection{The formation of polymer products upon the electrochemical reduction of white phosphorus}

In the following conditions: DMF vs. $0.1 \mathrm{M}$ solution of $\mathrm{Et}_{4} \mathrm{NBF}_{4}$ at $\mathrm{E}=-2.1 \mathrm{~V}$ and $\mathrm{C}_{\mathrm{P} 4}=50 \mathrm{mM}$ is confirmed by the microscopic images of the electrode surface (Figs. 2 and 3). The view of the polyphosphorus films depends on the electrolysis conditions and duration. The polyphosphorus products formed at the Pt electrode in DMF are rapidly dissolved and desorbed to the electrolyte volume. At the same time, on the lead cathode in DMF they form a black sponge nanoporous film (see Figs. 2 and 3). In a water containing electrolyte, a black poly- 
phosphorus conducting film is also formed, but the structure of polyphosphides is filamentous and needle-like in this case (see Fig. 3 ). The thickness of the polymer filaments is $\sim 1 \mu \mathrm{m}$.

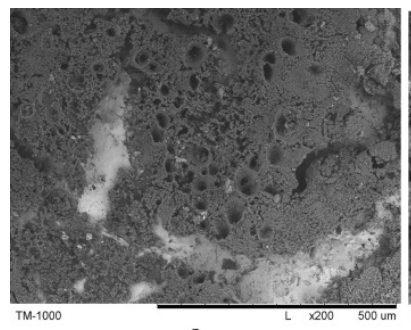

a

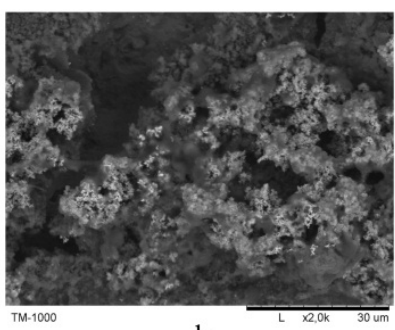

b

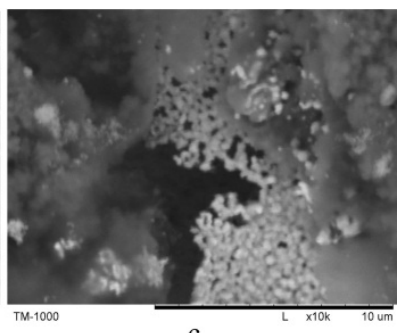

$\mathrm{c}$

Figure 2. View of the polyphosphorus films upon the electrochemical reduction of P4 in DMF vs. $0.1 \mathrm{M}$ solution of $\mathrm{Et}_{4} \mathrm{NBF}_{4}$ detected with a HITACHI TM-1000 microscope with a magnify cation of 200 (a), 2000 (b), and 10000 times (c).

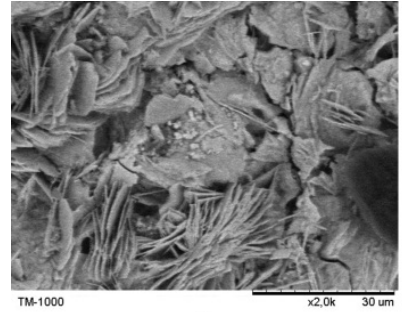

a

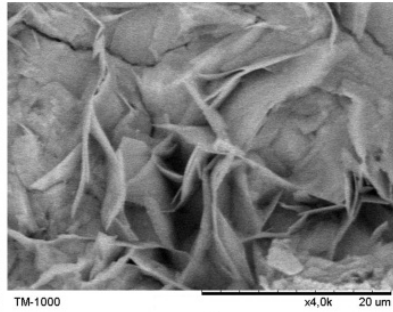

b

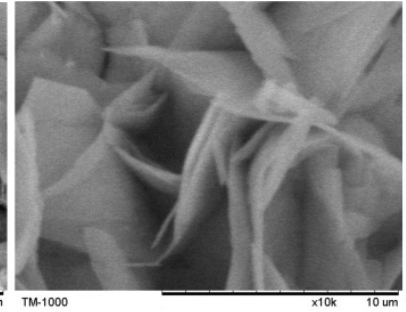

$\mathrm{c}$

Figure 3. View of the polyphosphorus films upon the electrochemical reduction of P4 in an aqueous solution of $\mathrm{HCl}$ detected with a HITACHI TM-1000 microscope with a magnification of 2000 (a), 4000 (b), and 10000 times (c).

\subsection{CVA of white phosphorus}

The electrochemical reduction of white phosphorus was not studied in details up to now, the mechanism of its activation and transformation with P-P bond cleavage under electron transfer on electrodes of the various nature was not clear. The data on potentials of $\mathrm{P}_{4}$ reduction on glassy carbon and mercury were published earlier [23], the ways of transformation of white phosphorus under the complexes of nickel, including generated electrochemically were described [29-31].

Research of an opportunity and a mechanism of heterogeneous activation of white phosphorus on various electrodes, finding-out of the factors determining ways of transformation of white phosphorus in polyphosphoric cycles, detection of short-living intermediates with the purpose of management of capture processes of highly reactive phosphoric oligomer forms $\left[\mathrm{P}_{\mathrm{n}}\right]^{\mathrm{m}-}$ by various substrata for example, olefins, at their joint reduction, represent a special interest. Simultaneous voltammetry (with linear or cyclic potential scan) and ESR allow to throw light on details of the mechanism of electron transfer processes. 
The purpose of the present work is the establishment of laws of reduction of white phosphorus on various electrodes (platinum (Pt), glassy carbon (GC), lead $(\mathrm{Pb})$ ), the mechanism of electron transfer and the nature of intermediates with application of methods of simultaneous voltammetry and ESR-spectroscopy.

It was revealed that potentials of $\mathrm{P}_{4}$ reduction and also currents and accordingly number of transferable electrons differ a little on various electrodes (Figs. 4-6 and Table 1). So, on glassy carbon electrode (Fig. 4) the reduction wave of white phosphorus is close to one-electronic, and on platinum (Fig. 5) and lead ones (Fig. 6) it is a little bit more one-electronic at use of benzophenon as the standard. The current of reduction is directly proportional to concentration of a substratum. Potentials of reduction settle down in the following sequence-the least negative is on a lead electrode, then on glassy carbon electrode, and the most negative-on platinum one.

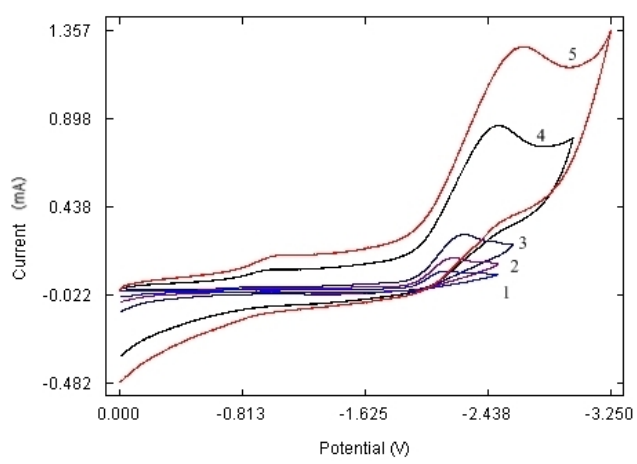

Figure 4. CVAs of white phosphorus solutions $(10 \mathrm{mM})$ in DMF on GC electrode. Potential: $V$ vs. SCE. Scan rate (bottom-up): $1-50 \mathrm{mV} / \mathrm{s}, 2-100 \mathrm{mV} / \mathrm{s}, 3-300 \mathrm{mV} / \mathrm{s}, 4-1000 \mathrm{mV} / \mathrm{s}, 5-10000 \mathrm{mV} / \mathrm{s}, 6-25000 \mathrm{mV} / \mathrm{s}$.

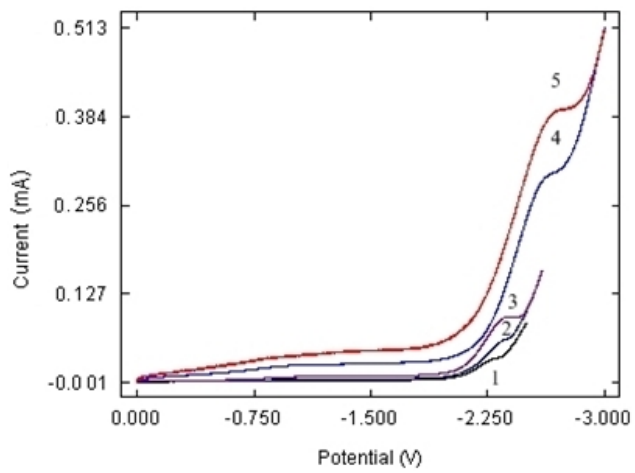

Figure 5. CVAs of white phosphorus solutions $(10 \mathrm{mM})$ in DMF on Pt electrode. Potential: $V$ vs. SCE. Scan rate (bottomup): $1-100 \mathrm{mV} / \mathrm{s}, 2-300 \mathrm{mV} / \mathrm{s}, 3-1000 \mathrm{mV} / \mathrm{s}, 4-10000 \mathrm{mV} / \mathrm{s}, 5-25000 \mathrm{mV} / \mathrm{s}$ 


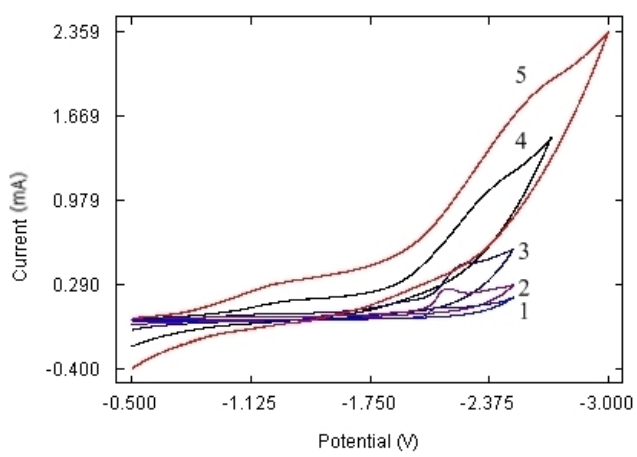

Figure 6. CVAs of white phosphorus solutions $(10 \mathrm{mM})$ in DMF on Pb electrode. Potential: $V$ vs. SCE. Scan rate (bottom-up): $1-50 \mathrm{mV} / \mathrm{s}, 2-100 \mathrm{mV} / \mathrm{s}, 3-300 \mathrm{mV} / \mathrm{s}, 4-1000 \mathrm{mV} / \mathrm{s}, 5-10000 \mathrm{mV} / \mathrm{s}, 6-25000 \mathrm{mV} / \mathrm{s}$.

\begin{tabular}{ccc}
\hline Electrode & $\mathbf{n}_{\mathbf{e}}$ & $-\mathbf{E}, \mathbf{V}$ \\
\hline $\mathrm{GC}$ & 1.01 & 2.16 \\
\hline $\mathrm{Pt}$ & 1.30 & 2.30 \\
\hline $\mathrm{Pb}$ & 1.27 & 2.12 \\
\hline
\end{tabular}

Table 1. Characteristics of reduction pics of white phosphorus. DMF, $10 \mathrm{mM} \mathrm{P}_{4}, 0.1 \mathrm{M} \mathrm{Et}_{4} \mathrm{NBF}_{4}$, Scan rate: $100 \mathrm{mV} / \mathrm{s}$. Potential: V vs. SCE, standard-benzophenone.

An anodic component of wave is observed on the glassy carbon electrode at high potential scan at return scanning that can testify to some stability of a product of primary carry of an electron on a molecule of white phosphorus $\left[\mathrm{P}_{4}\right] \boldsymbol{\bullet}$. The process is completely irreversible on other electrodes. However it is visible by detailed consideration of character of voltammetric curves, that the peak has the complex form on GC at record of several cycles (Figs. 7a and $7 \mathrm{~b}$ ). Last is shown more distinctly at record of curves in coordinates «semi derivative of a current-potential» (Fig. 7b). The form of peak can be connected to polymerization of phosphorus on the electrode.

Coefficient of diffusion of white phosphorus and coefficient of transfer have been estimated (Table 2) on the basis of received voltammetric curves. Calculation was carried out on Delahey equation for irreversible processes [32]:

$$
i_{p}=\left(2,99 \cdot 10^{5}\right) \cdot n \cdot\left(\alpha n_{a}\right)^{1 / 2} \cdot S \cdot D^{1 / 2} \cdot v^{1 / 2} \cdot C_{o}
$$

where

$i_{p}$ - current, A; 
$n$ - number of electrons;

$\alpha$ - electron transfer coefficient;

$S$ - electrode surface, $\mathrm{cm}^{2}$;

$D$ - coefficient of diffusion, $\mathrm{cm}^{2} / \mathrm{s}$;

$v$ - scan rate, $\mathrm{V} / \mathrm{s}$;

$C_{0}$ - concentration, $\mathrm{mol} / \mathrm{cm}^{3}$.

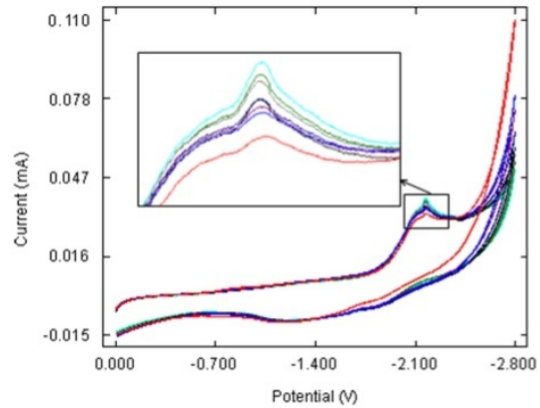

a

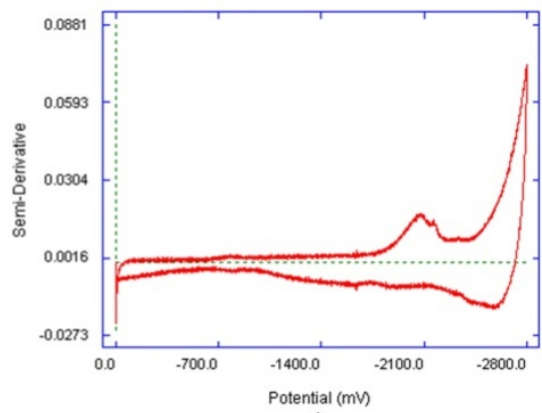

b

Figure 7. CVAs of white phosphorus solutions ( $5 \mathrm{mM}$ ) in DMF on GC electrode. Potential: V vs. SCE. Scan rate: 100 $\mathrm{mV} / \mathrm{s}$. a - CVA from 0 to $-2.8 \mathrm{~V}, \mathrm{~b}$ - dependence of semi-derivative of a current from potential.

Linear dependences of white phosphorus reduction current from $\sqrt{ }_{v}(v-$ scan rate) on all electrodes are observed. That process is diffusion controllable (Fig. 8).

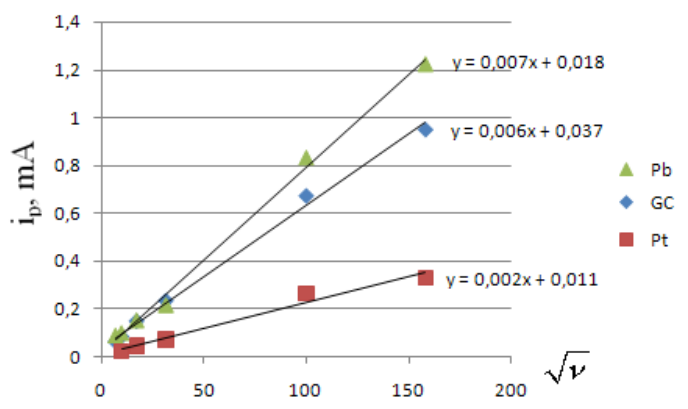

Figure 8. White phosphorus reduction peak current dependences on $\sqrt{ } v(v-s c a n$ rate) on various electrodes: GC, Pt, and $\mathrm{Pb}$.

The values of the transfer coefficient according Eq. (1): 


$$
\begin{gathered}
\alpha=\frac{R T}{F} \cdot \frac{1,85}{E_{p / 2}-E_{p}} \\
D=\left(\frac{i_{p}}{\left(2,99 \cdot 10^{5}\right) n \cdot \sqrt{\alpha n_{a}} \cdot \sqrt{v} \cdot C_{O}}\right)^{2}
\end{gathered}
$$

\begin{tabular}{cccccc}
\hline Electrode & $\boldsymbol{C}_{\boldsymbol{o}^{\prime}} \mathbf{m} \boldsymbol{M}$ & $\begin{array}{c}\text { Scan rate, } \\
\mathbf{m V} / \mathbf{s}\end{array}$ & $\boldsymbol{\Delta} \boldsymbol{E}_{\boldsymbol{p}^{\prime}} \mathbf{m V}$ & $\boldsymbol{a}$ & $\mathbf{D}, \mathbf{c m}^{2} / \mathbf{s}$ \\
\hline $\mathrm{GC}$ & 5 & 100 & -156 & 0.304 & $1.82 \times 10^{-5}$ \\
\hline $\mathrm{Pb}$ & 5 & 100 & -52 & 0.879 & $6.01 \times 10^{-6}$ \\
\hline $\mathrm{GC}$ & 10 & 100 & -123 & 0.386 & $2.06 \times 10^{-5}$ \\
\hline $\mathrm{Pb}$ & 10 & 100 & -43 & 0.931 & $1.39 \times 10^{-6}$ \\
\hline $\mathrm{Pt}$ & 10 & 100 & -112 & 0.424 & $2.67 \times 10^{-5}$ \\
\hline
\end{tabular}

Table 2. Calculation of coefficient of diffusion on various electrodes.

The average value of the coefficient of diffusion of white phosphorus calculated in DMF is 2 $\times 10^{-5} \mathrm{~cm}^{2} / \mathrm{s}$.

\subsection{Electrosynthesis of primary phosphines from alkenes and white phosphorus}

Primary phosphines are valuable starting materials in many chemical reactions. Because of their importance as precursors or active intermediates in many reactions, there is a growing interest in a new preparation method from an available raw material such as elemental phosphorus. Replacement of the present-day processes for preparation of basic organophosphorus compounds now based on reactions of phosphorus chlorides is becoming increasingly important. The existing processes are environmentally dangerous, energy-demanding and cause problematic waste streams. The creation of chlorine- and waste-free processes aimed at the obtaining of some starting compounds, namely, phosphites, phosphates, amides and tertiary phosphines, etc., based on elemental phosphorus is an alternative of the organophosphorus compounds synthesis.

The syntheses of primary phosphines usually involve expensive, multi-step and long-term procedures, such as: the use of reduction of phosphorus dihalides with $\mathrm{LiAlH}_{4}$, preparation from metal phosphides and alkyl or aryl halides, hydrolysis of alkyl and arylphosphorus dihalides, reaction under Friedel-Crafts conditions, pyrolysis of biphosphines and triphosphines, etc. $[10,33,34]$. Selective method of primary phosphine preparation directly from white phosphorus escaping, traditional stages of its chlorination, with formation of unique phosphorus compounds with phosphorus-carbon bond is not known up to now. 
Reactions of olefines with phosphorylating agents are not selective as a rule. It is known [11], that styrene reacts with $\mathrm{PH}_{3}$ at $70^{\circ} \mathrm{C}$ and a pressure of 28-30 atmospheres under the action of radical initiators. This reaction results in the formation of the mixture of primary, secondary, and tertiary phosphines with the yields of $6-36 \%$. The way of primary phosphines preparation from styrene or $\alpha$-methylstyrene and $\mathrm{PH}_{3}$ in superbasic medium (KOH/DMSO) with the yield of $20-30 \%$ are also well known [9].

Electrochemical methods of action on white phosphorus are found to be very promising in many cases, since they allowed elaborating the procedures of selective synthesis of phosphorus acid esters, triphenylphosphines and other products [35-37].

However up to now one failed to elaborate an approach to synthesize from $\mathrm{P}_{4}$ phosphine derivatives with one or two $\mathrm{P}-\mathrm{H}$ bonds, e.g. primary or secondary phosphines $\mathrm{R}_{2} \mathrm{PH}, \mathrm{RPH}_{2}$, tertiary phosphines other than triphenylphosphine, phosphorus acids $\mathrm{H}_{3} \mathrm{PO}_{3}, \mathrm{H}_{3} \mathrm{PO}_{2}$ and others, being important precursors in phosphorus chemistry. The main problem of all known reactions concerns either low yield of a product due to the formation of nonreactive polyphosphides and consequently low phosphorus conversion, or the use of expensive reagents, such as rhodium complexes [38-40]. Our attention was attracted by rather old publications on phosphine electrolytic production, which were carried out already in the sixties 20th centuries and for some reason did not receive further progression. Thus, the cathodic reduction of white phosphorus in aqueous solutions on metals with high hydrogen overvoltage was shown to result in the formation of $\mathrm{PH}_{3}$ with yield up to 95\%; these results were patented in Germany, USA, and Great Britain [41-47]. Recently, some technological refinement for this process was suggested by Japanese researchers, who patented a turbulent generating process of $\mathrm{PH}_{3}$ [48]. In the sixties 20th centuries and at the beginning of the seventies 20th centuries several attempts were undertaken to use electrochemically generated $\mathrm{PH}_{3}$ for subsequent synthesis on the base of its reactions in situ, however, the obtained results were not encouraging as they resulted in complex mixtures of products (e.g. with styrene) [14-16] and/or low yields.

It is worth noting that the direction of white phosphorus conversion into phosphine is sufficiently well worked out by patents, and the present task consists in creation of such conditions, which would allow instant (as formed) conversion of $\mathrm{PH}_{3}$ and other phosphine intermediates into the derivatives with $\mathrm{P}-\mathrm{H}$ bonds, e.g. organic phosphines. This will allow avoiding the accumulation of intermediate toxic and dangerously explosive phosphine, converting it into undetectable "conventional intermediate":

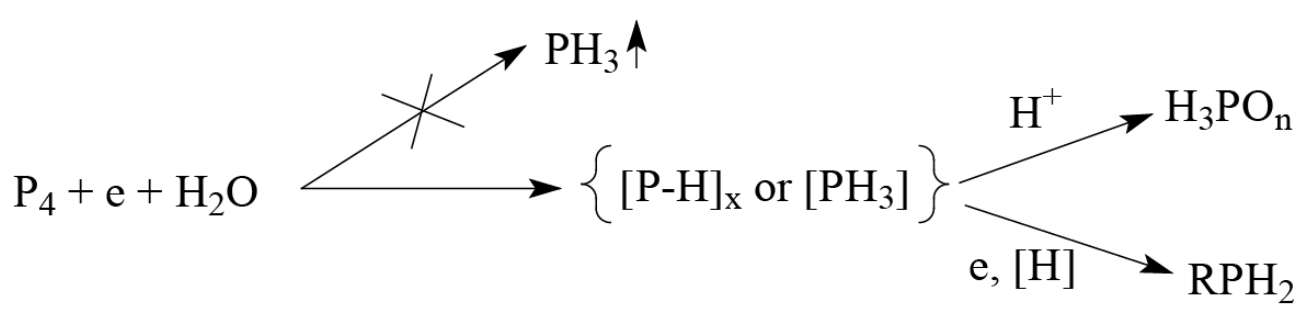

Scheme 4. Electrolysis $\mathrm{P}_{4}$ in aqueous solution. 
Joint electrolysis of white phosphorus emulsion and alkene in the aqueous acetic buffer solution results in the formation of just primary phosphine in these conditions (Table 3):

$$
1 / 4 \mathrm{P}_{4}+\mathrm{CH}_{2}=\mathrm{CH}-\mathrm{R} \stackrel{3 \mathrm{H}^{+}, 3 \mathrm{e}}{\longrightarrow} \mathrm{H}_{2} \mathrm{P}-\mathrm{CH}_{2} \mathrm{CH}_{2}-\mathrm{R}
$$

Scheme 5. Formation primary phosphine from $\mathrm{P}_{4}$ in aqueosu acetic buffer solution.

The mechanism of phosphine with P-C bond formation is not quite clear. It should be assumed as follows, that phosphorus centered radicals and radical-anions are generated from white phosphorus under conditions of electrochemical reduction. Radicals and radicalanions can add to weakly electrophilic alkenes (e.g. styrene) by the nucleophilic mechanism, and to nucleophilic alkenes (alkyl ethene, phenyl ethers)-by the radical mechanism.

Electrochemical reduction of $\mathrm{P}_{4}$ molecule in protogenic conditions is known to take place at the cathode with high hydrogen overvoltage, for example, at the lead cathode [35-37]. The electrochemical rupture of the P-P bonds, resulting in the formation of phosphine, is provided by the presence of active proton donors through the protonation of intermediates:

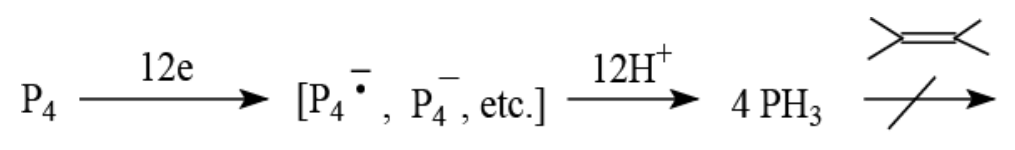

Scheme 6. Electrochemical reduction of $\mathrm{P}_{4}$ molecule.

But on the other hand, phosphine does not react with alkene without catalyst. Phosphine can be added to $\mathrm{C}=\mathrm{C}$ bonds both by ionic and radical mechanisms in the presence of initiators. Alkenes of different structure react with phosphine under rather rigid conditions (60-90 $\mathrm{C}, 30-47 \mathrm{~atm}$, acid catalyst; or in the superbasic medium such as $\mathrm{KOH} / \mathrm{DMF}$ ) [34]. Apparently, under electrolysis conditions the reaction under investigation is initiated by phosphine reduction to $-\mathrm{PH}_{2}$, occurring at the electrode, or proceeds through the intermediate phosphides or radical and radical-anions formed at white phosphorus reduction. Generally, it is impossible to exclude proceeding of several competitive reactions of phosphide-anion formation, both its protonation in solution and reduction of $\mathrm{P}-\mathrm{H}$ bond at the electrode, and target addition of phosphide-anion to alkene.

Voltammetric (coulometric) studies of white phosphorus reduction were performed at mercury electrode in alcohol medium [49] and have shown the process to proceed at substantial negative potentials, the calculation of a number of electrons through the peak height giving the value of $n$ close to unity in the concentration range from 0.05 to $1.6 \mathrm{mM}$, what practically coincides with white phosphorus solubility limit in these media. At glass carbonic electrode in aprotic media (DMFA, $\mathrm{CH}_{3} \mathrm{CN}$ ) with modest addition of benzene the process proceeds at $-2.20 \mathrm{~V}\left(\mathrm{Ag} / \mathrm{AgNO}_{3}\right)$, at concentration $5 \mathrm{mM}$ a number of electrons being even slightly smaller than unity- 0.7 with benzophenone standard [30]. At lead electrode white phosphorus reduces at similar values of potential $\left(-2.20 \mathrm{~V}\right.$ vs. $\mathrm{Ag} / \mathrm{AgNO}_{3} ;-1.86 \mathrm{~V}$ vs. SCE) and current. To understand the mechanism of white phosphorus reduction one may consider the variation 
of phosphorus concentration with the amount of transmitted current according to the A.P. Tomilov procedure $[14,50]$. In doing so the methanol solution admixed with benzene and styrene, which is not indifferent to phosphorus in conditions of reduction, is changed for inert solvent, e.g. dimethylformamide admixed with benzene or toluene to improve solubility. According to the calculation, the loss of phosphorus at the beginning of electrolysis corresponds to the one-electron process, and then phosphorus concentration becomes so low, that the voltammetry does not provide reliable results. Visual observation demonstrates after nearly $0.5 \mathrm{~F} / \mathrm{R}$ the formation of dark oily liquid not solidifying (hardening) at room temperature, insoluble in aqueous media and instantly flaring up in the air; this liquid is to a large measure adsorbed at a leaden cathode and disappears after transmitting of $3 \mathrm{~F} / \mathrm{R}$. In aprotic media a considerable amount of white phosphorus converts into insoluble yellow polyphosphides frequently observed at $\mathrm{P}_{4}$ exposure to nucleophilic reagents. In that way the loss of white phosphorus in a solution occurs much faster than it is required for three-electron process (Fig. 9).

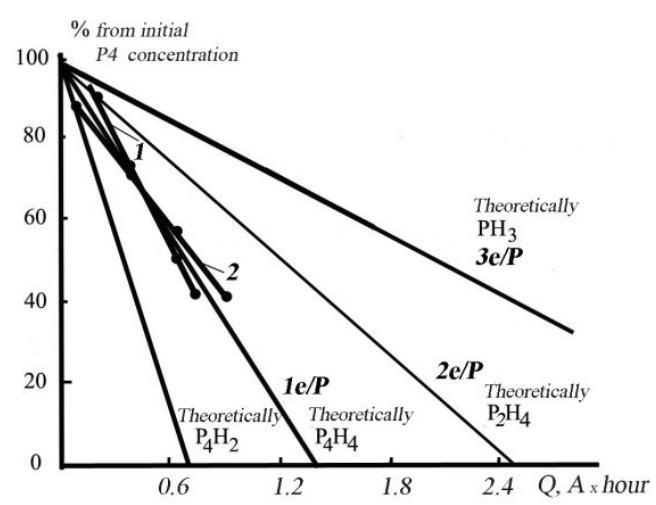

Figure 9. Measurement of phosphorus concentration in KAc/HAc solution in DMF with a mixture of benzene (1) and toluene (2) in the process of cathodic reduction at lead electrode.

Thus, one may conclude that first two of three possible reactions do not occur at the initial stage of electrolysis:

$$
\begin{array}{ll}
\mathrm{P}_{4}+12 \mathrm{e} \stackrel{+12 \mathrm{H}^{+}}{\longrightarrow} 4 \mathrm{PH}_{3} \uparrow & 3 \mathrm{e} / \mathrm{P} \\
\mathrm{P}_{4}+8 \mathrm{e} \stackrel{+8 \mathrm{H}^{+}}{\longrightarrow} 2 \mathrm{P}_{2} \mathrm{H}_{4} & 2 \mathrm{e} / \mathrm{P} \\
\mathrm{P}_{4}+4 \mathrm{e} \stackrel{+4 \mathrm{H}^{+}}{\longrightarrow} \mathrm{P}_{4} \mathrm{H}_{4} & 1 \mathrm{e} / \mathrm{P}
\end{array}
$$

Scheme 7. Stage of electrolysis of $\mathrm{P}_{4}$. 
Phosphorus one-electron reduction results in the formation of phosphorus hydride $\mathrm{P}_{4} \mathrm{H}_{4}$. Cyclic $\mathrm{P}_{4} \mathrm{H}_{4}$ is not available in literature, though its existence is supposed in the series of hydrides of the $(\mathrm{PH})_{x}$ type $[10,51] . \mathrm{P}_{4} \mathrm{H}_{4}$ is insoluble in water; it is known to have melting temperature $99^{\circ} \mathrm{C}$, boiling temperature $56^{\circ} \mathrm{C}$ [51]. Evidently, at the early stages of electrolysis there occurs the formation of hydrides, which are water-insoluble, but are well soluble in phosphorus, with the curing temperature being decreased and coloring being darkened. Liquid phosphorus hydride, withdrawn from the electrolyzer, decomposes at light under water with solid yellow polyphosphoric products being formed. It is interesting, that in the considered aqueous solutions white phosphorus is practically insoluble, and however, nevertheless it efficiently reduces at leaden cathode at $\mathrm{P}_{4}$ emulsification. This phenomenon is explained by the so-called "wick effect": molten phosphorus lifts vertically along the cathode similarly to the liquid along the wick, moistening its whole surface [51].

The formation of secondary or tertiary phosphines was not observed even at significant alkene excess in initial mixture. According to NMR ${ }^{31} \mathrm{P}$ spectrum, the only by-products discovered in the reaction mixture in aqueous part of electrolyte were inorganic acids of phosphorus. The proposed method is characterized by the following advantages: mild conditions (room temperature) of the process and the one-step way of primary phosphine preparation directly from white phosphorus escaping all traditional stages of its functioning.

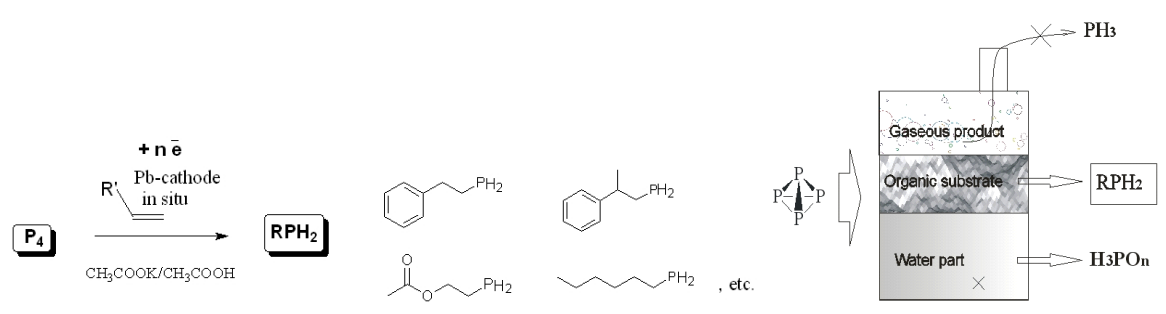

Scheme 8. Products of electrolysis of white phosphorus in water-phosphines and its derivatives (organic and inorganic).

It should be noted that the use of some alkenes does not afford an opportunity of the desired phosphines formation (Table 3).

The results, obtained in the course of electrosynthesis, are explained on the basis of the voltammetric data for substrates. According to cyclic voltammetry data, reduction potentials of alkene, successfully reacting with $\mathrm{P}_{4}$ in joint electrolysis (first four lines in Table 3), are more negative, than the potential of white phosphorus reduction $(E=-2.2 \mathrm{~V})$. Therefore, the process proceeds through $\mathrm{P}_{4}$ reduction to the desired products. Other alkenes (last four lines in Table 3) are reduced more easily than phosphorus, what hinders the primary phosphines formation. Limitation of the process is caused by obtaining only phosphines with $\mathrm{H}_{2} \mathrm{P}-$ $\left(\mathrm{CH}_{2}\right)_{2}$-bonds. 


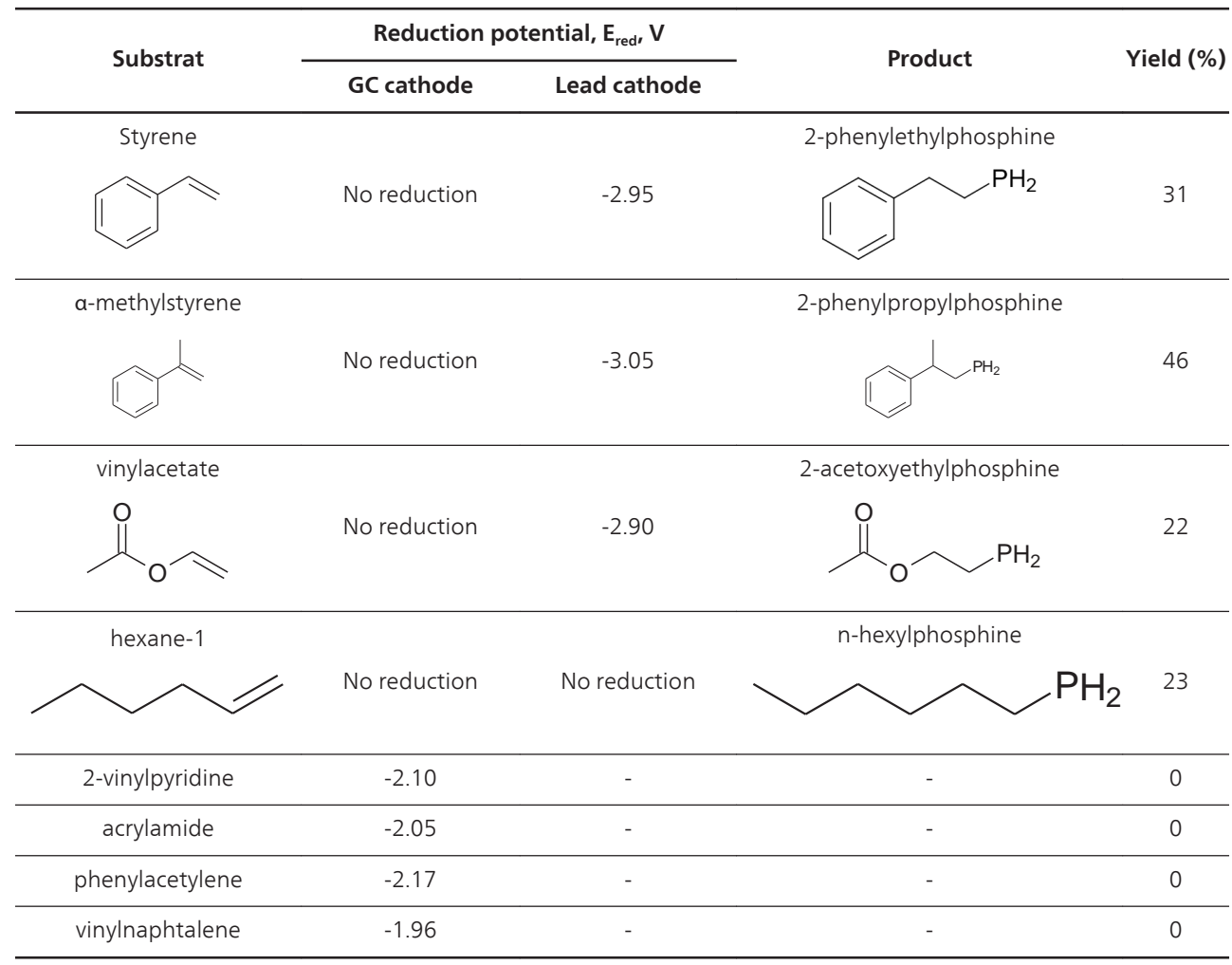

Table 3. Reduction potentials of initial alkenes and yields of their phosphorylation products.

\subsection{Electrocatalyzed functionalization of white phosphorus in the presence of nickel complexes}

The electrocatalytic functionalization of white phosphorus has been also accomplished using transition metal complexes as catalysts [52-55].The activation of $\mathrm{P}_{4}$ takes place under mild conditions promoted by the electrogeneration of a carbanion in the presence of $\mathrm{P}_{4}$ [30,53-55]. The reaction has been documented for $\mathrm{Ni}(0)$ species stabilised by $2.2^{\prime}$-bpyridine (bpy) electrogenerated from $\mathrm{Ni}(\mathrm{II})$ complexes. The reduced $\mathrm{Ni}(0)$ species react with organic halides to give $\sigma$-organonickel complexes which may further participate in several organic elaborations of different substrates, including phosphorus [22,35,53-55].In such a case, the electrolysis is carried out using a soluble electrode $(\mathrm{Al}, \mathrm{Mg}, \mathrm{Zn})$ in an undivided cell with a phosphorus emulsion in DMF or acetonitrile containing an organic halide and a Ni(II) complex, $\left[\mathrm{Ni}(\mathrm{bpy})_{3}\right]\left(\mathrm{BF}_{4}\right)_{2}$, as catalyst. Under these experimental conditions, white phosphorus may be efficiently converted to phosphines and phosphine oxides [53-55].

Mechanistic studies were carried in the specific case of electrocatalytic arylation of white phosphorus [53-55]. From these investigations, it was determined that the $\mathrm{Ni}(0)$ complex, in- 
itially obtained via reduction of $\mathrm{Ni}(\mathrm{II})$, oxidatively adds the organic halide to give [NiX(Ar) (bpy)] species, which mediate the catalytic formation of $\mathrm{P}-\mathrm{C}$ bonds.
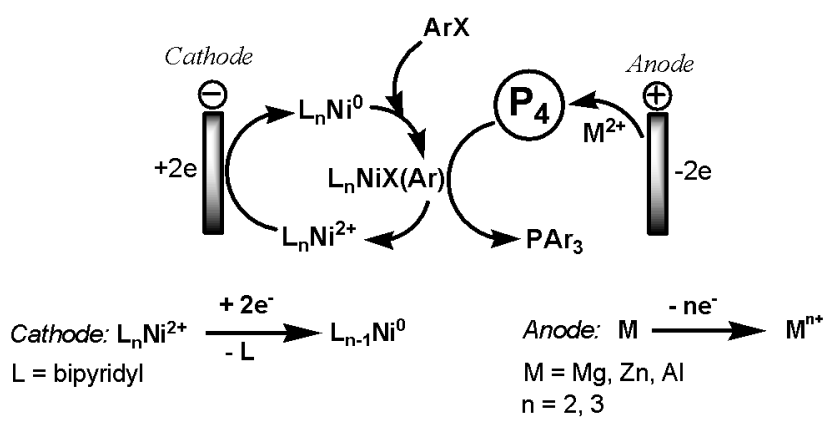

Scheme 9. Representation of the nickel electrocatalyzed arylation of white phosphorus.

The nature of the soluble anode drastically influences the final product although such a behaviour denies any simple interpretation (Sch. 10). Then, the use of a zinc anode leads to complete conversion of $\mathrm{P}_{4}$ to soluble OPCs, mainly, tertiary phosphines, while an aluminium anode electrogenerates the phosphine oxide. Cyclic polyphosphorus compounds, such as $(\mathrm{PhP})_{5}$, are produced when a magnesium anode is used [35,53-55].

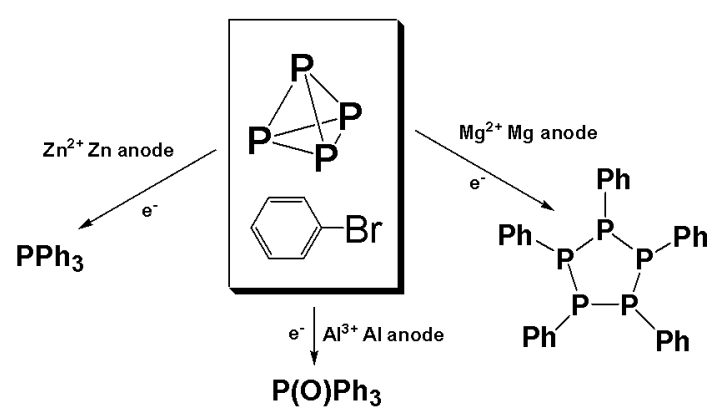

Scheme 10. Electrode dependence of the product resulting from the electrocatalyzed arylation of white phosphorus with bromobenzene.

These processes are intriguing because they underpin the high potentiality of metal electrocatalysis in bringing about the alkylation and arylation of white phosphorus under mild conditions. Remarkably, these processes combine a high efficiency in OPC formation with a total control of the product selectivity depending on the careful choice of the metal anode.

We have developed essentially new approach to triphenyl- or perfluoroalkylphosphine preparation from white phosphorus, using not divided electrolyzer and activation of white phosphorus under the action of zinc compounds: 


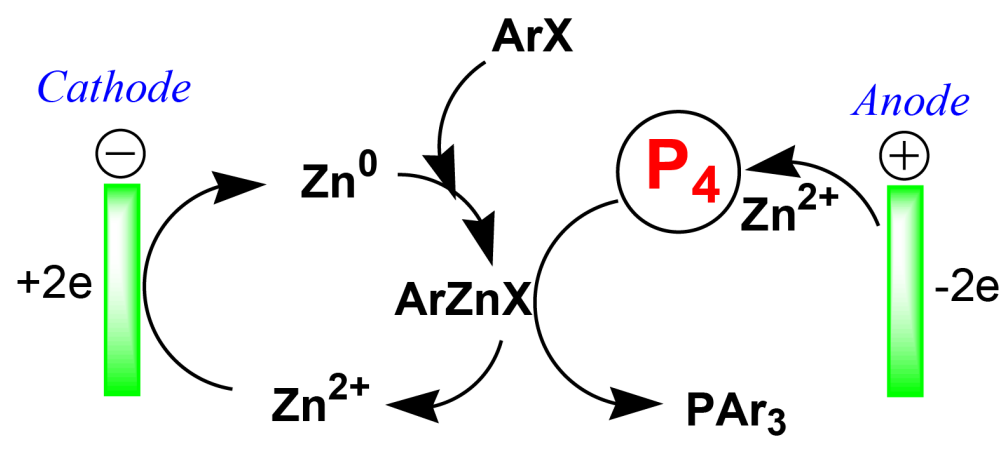

Scheme 11. Representation of the Zn catalyzed arylation of white phosphorus.

Cyclic regeneration of $\mathrm{Zn}$-catalyst takes place at the cathode, reactive sigma-complex forms in the bulk of the solution. The $\sigma$-complex attacks the $\mathrm{P}_{4}$ molecule resulting in tertiary phosphines as target product.

\section{Conclusions}

Combining electrochemistry with homogeneous catalysis offers many interesting opportunities for the direct application to the synthesis of organophosphorus derivatives. As the electrochemical equipment and the adopted procedures become more and more simple, it is expected that electrochemical methods will successfully compete with the conventional synthetic methods. The former allow carrying out the wished synthesis avoiding the use of chlorine and under mild conditions with high reaction rates and good productivities. They also permit a fine-tunable control of the process resulting therefore in high or sometimes complete selectivity. Thus, electrosynthesis allows single-stage converting of white phosphorus and alkenes under mild conditions into primary products, being the single products with phosphorus-carbon bond. Inorganic hypophosphorus acid is found to be a by-product. The choice of alkenes is defined by their smaller electrochemical activity at glass-carbon electrode they are not reduced in the accessible region, while at leaden electrode they reduce at lower negative potentials.

The $\mathrm{P}^{\bullet-}$ radical anion was detected for the first time in the potentiostatic mode by the ESR method as the spin-adduct with $\alpha$-phenyl- $N$-tert-butylnitrone in the electrochemical reduction of white phosphorus in the electrolysis cell with the helical platinum working electrode. The present study confirms the radical character of the intermediates of white phosphorus.

The base to realization of the developed processes of organophosphorus compounds preparation from elemental phosphorus at the technological level was incorporated as a result. Scientific bases highly effective, resource saving and ecologically safe technology of electrosynthesis of the major classes of OPC were created. The block diagram of synthesis and sep- 
aration of a target product was made. The technological instruction of process was developed.

There are many interesting promising synthetic applications combining electrochemistry with homogeneous catalysis.

The interest to the organophosphorus compounds electrosynthesis on the basis of white phosphorus is also caused by a number of advantages compared to common chemical methods:

- No additional chemicals; a possibility to carry out the reaction in practically closed system with minimum amount of cyclically regenerated reagents;

- Greater product selectivity and yield

- Reduced or no disposal cost

- Recovery, recycling of astes/pollutants

- Low capital costs/low operating costs.

Essentially, new approach to OPC synthesis, having practical value, from white phosphorus in electrocatalytic conditions, first of all with $\mathrm{P}-\mathrm{C}$ or P-H bonds based on effective universal technology of electrosynthesis of lines of OPC compounds were created.

The electrochemistry is a powerful synthetic method for preparing a wide range of phosphorus compounds.

\section{Author details}

Yu. G. Budnikova and S. A. Krasnov

A. E. Arbuzov Institute of Organic and Physical Chemistry Kazan Scientific Center, Russian Academy of Sciences, Russia

\section{References}

[1] Kolbe H. Untersuchungen über die Elektrolyse organischer Verbindungen. Annalen der Chemie und Pharmacie. 1849;69(3) 257-372.

[2] Degner D. Organic electrosyntheses in industry. Topics in Current Chemistry; 1988,148 .

[3] Budnikova Yu.H. Electrosynthesis of organic compounds. Ecologically safe processes and design of new synthetic methods. Rossijskij Khimicheskij Zhurnal (Zhurnal Rossijskogo Khimicheskogo Obshchestva Im. D.I. Mendeleeva). 2005;49(5) 81-93. 
[4] Budnikova Yu.H. Metal complex catalysis in organic electrosynthesis. Russian Chemical Reviews. 2002;71(2) 111-139.

[5] Utley J. Trends in organic electrosynthesis. Chemical Society Reviews. 1997;26(3) 157-167.

[6] Kargin Yu. M., Budnikova Yu. H. Electrochemistry of organophosphorus compounds. Russian Journal of General Chemistry. 2001; 71(9) 1393-1421.

[7] Amatore C., Jutand A. Mechanistic and kinetic studies of palladium catalytic systems. Journal of Organometallic Chemistry. 1999;576 (1-2) 254-278.

[8] Kadirov M. K., Odivanov V. L., Budnikova Yu. G. Pribory I tekhnika eksperimenta [Experimental Instruments and Technique], 2007;1(151) (in Russian).

[9] Gusarova N.K., et al. Synthesis primary phosphines from phosphine and arylethylenes. Russian Chemical Bulletin. 1995; 8 1597-1598.

[10] Corbridge D.E.C. Phosphorus 2000. Chemistry, Biochemistry\&Technology. Elsevier, Amsterdam/Lausanne/New York/Oxford/Shannon/Singapore/Tokyo; 2000.

[11] Rauhut M.M., et al. The free radical addition of phosphines to unsaturated compounds. Journal of Organic Chemistry. 1961;26(12) 5138-5145.

[12] Pass F., Schindlbauer H. Organische Verbindungen des Phosphors. I. Mitt. - Über die Darstellung primärer Phosphine durch reduktive Methoden. Monatshefte für Chemie. $1959 ; 90(2)$ 148-156.

[13] Knunjanz I.L. and Sterlin R.N., Doklady AN SSSR (Russ.).1947;1 47-50.

[14] Shandrinov N.Ya., Tomilov A.P. Electrocemically reduction of phosphorus on a lead electrode. Electrochemistry. 1968;4 237.

[15] Osadchenko I.M., Tomilov A.P. Electrochemical synthesis of hydrogen phosphide. Zhurn. prikl. Khimii. 1970;43 1255

[16] Osadchenko I.M., Tomilov A.P. Syntesis lower acids of phosphorus by electrolysis of suspension red phosphorus. Electrochemistry. 1993;29(3) 406.

[17] Tsuchiya H., Otsuji A., Sakagami Yu., Japan Patent 01139781 A2 19890601 Heisei, 1989.

[18] Barry M.L., Tobias Ch. W., Electrochimical Technology. 1966;4 502.

[19] US Patent 4,021,321 (Cl.204-103; C25B1/22), (1977).

[20] US Patent 4,021,322 (Cl.204-103; C25B1/22), (1977).

[21] Peruzzini M., Abdreimova R. R., Budnikova Y., Romerosa A., Scherer O. J., Sitzman $\mathrm{H}$. Functionalization of white phosphorus in the coordination sphere of transition metal complexes. Journal of Organometallic Chemistry. 2004;689 4319-4331. 
[22] Milyukov V.A, Budnikova Yu.H., Sinyashin O.G. Organic chemistry of elemental phosphorus. Russian Chemical Reviews. 2005;74 781.

[23] Budnikova Yu. G., Krasnov S. A., Sinyashin O. G. Design of ecologically safe and science intensive electrochemical processes. Russian Journal of Electrochemistry. 2007;43(11) 1223-1228.

[24] M. K. Kadirov, Patent. RF 69 252. Byul. Izobret. [Invention Bulletin]. 2007; 34 (in Russian).

[25] Janzen E. G. Spin trapping. Accounts of Chemical Research. 1971;4(1) 31-40.

[26] Bard A.J., Gilbert J.C., Goodin R.D. Application of spin trapping to the detection of radical intermediates in electrochemical transformations [30]. Journal of the American Chemical Society. 1974;96(2) 620-621.

[27] The National Institute of Environmental Health Sciences. Search the Spin Trap Database. http://epr.niehs.nih.gov.

[28] Zeng Y., Zheng Y., Yu Sh., Chen K., Zhou Sh. An ESR study of the electrocatalytic oxidation of hypophosphite on a nickel electrode. Electrochemistry Communications. 2002;4(4) 293-295.

[29] Budnikova Yu.H., Tazeev D.I., Trofimov B.A., Sinyashin O.G. Electrosynthesis of nickel phosphides on the basis of white phosphorus. Electrochemistry Communications. 2004;6(7) 700-702.

[30] Budnikova Yu.G., Tazeev D.I., Kafiyatullina A.G., Yakhvarov D.G., Morozov V.I., Gusarova N.K., Trofimov B.A., Sinyashin O.G. Activation of white phosphorus in the coordination sphere of nickel complexes with $\sigma$-donor ligands. Russian Chemical Bulletin. 2005;54(4) 942-947.

[31] Budnikova Yu.G., Tazeev D.I., Gryaznova T.V., Sinyashin O.G. Novel high-efficiency ecologically safe electrocatalytic techniques for preparing organophosphorus compounds. Russian Journal of Electrochemistry. 2006;42(10) 1127-1133.

[32] Bard A.J., Faulkner L.R., Electrochemical Methods: Fundamentals and Applications, second ed., New York, 2001.

[33] Kosolapoff G.M. and Maier L. Organic Phosphorus Compounds. John Wiley and Sons, New York/London/Sydney/Toronto. 1976;7 871 pp.

[34] Trofimov B.A., et al. Phosphine in the synthesis of organophosphorus compounds. Russian Chemical Reviews. 1999;68(3) 215-227.

[35] Budnikova Yu. H., Yakhvarov D., Sinyashin O.G. Electrocatalytic eco-efficient functionalization of white phosphorus. Journal of Organometallic Chemistry. 2005;690(10) 2416-2425.

[36] Budnikova Yu. H., Kargin Yu.M., Romakhin A.S., Sinyashin O.G. Patent Russian Federation № 2199545.2003. 
[37] Budnikova Yu. H., Yakhvarov D.G., Sinyashin O.G. Patent Russian Federation № 2221805. 2004.

[38] Di Vaira M., Frediani P., Seniori Costantini S., Peruzzini M., Stoppioni P., Dalton Trans. Easy hydrolysis of white phosphorus coordinated to ruthenium. Dalton Transactions.2005;(13) 2234-2236.

[39] Barbaro P., Peruzzini M., Ramirez J. A., Vizza F. Organometallics 18 (1998) 2376.

[40] Barbaro P., Peruzzini M., Ienco A., Mealli C., Scherer O. J., Schmitt G., Vizza F., Wolmershäuser G. Activation and Functionalization of White Phosphorus at Rhodium: Experimental and Computational Analysis of the [(triphos)Rh ( $\eta$ 1:ๆ2-P4RR $\left.\left.{ }^{\prime}\right)\right] Y$ Complexes (triphos = MeC(CH2PPh2)3; R = H, Alkyl, Aryl; $\mathrm{R}^{\prime}=2$ Electrons, $\mathrm{H}, \mathrm{Me}$ ). Chemistry - A European Journal. 2003;9(21) 5195-5210.

[41] Patent USA 3109790 (1963); C.A. 60, 2552. 1964.

[42] Patent USA 3109791 (1963); C.A. 60, 2552. 1964.

[43] Patent USA 3109792 (1963); C.A. 60, 2552. 1964.

[44] Patent. Germany 1210424 (1966); C.A. 64, 13767d. 1966.

[45] GB Patent 1042391. 1966.

[46] Patent Germany 1210425 (1966); C.A.64, 13767f. 1966.

[47] Patent Germany 1210426 (1966); C.A.64, 12198g. 1966.

[48] Patent Japan 01139781 A2 19890601 Heisei. 1989.

[49] Tomilov A.P., Mairanovskii S.G., Fioshin M.Ya., Smirnov V.A. Electrochemistry of Organic Compounds. «Khimiya. Leningrad», 1968591.

[50] Tomilov A.P., Osadchenko I.M. Journal AnalitycalChemistry (Russian). 1966; 1498.

[51] Osadchenko I. M., Tomilov A.P. Electrocemically synthesis of phosphine oxide. Russian Chemical Review. 1969;38(6) 1089-1107.

[52] Budnikova Yu.H., Yakhvarov D.G., Kargin Yu.M. Coordination Catalysis in Organic Electrosynthesis. Electrochemical Phosphorylation of Organic Halides in the Presence of Samarium Dichloride. Russian Journal of General Chemistry. 1998;68(4) 566-569.

[53] Budnikova Yu.H., Yakhvarov D.G., Kargin Yu.M. Arylation and alkylation of white phosphorus in the presence of electrochemically generated nickel(0) complexes. Mendeleev Communication. 1997;7(2) 67-68.

[54] Budnikova Yu. H., Perichon J., Yakhvarov D.G., Kargin Yu.M., Sinyashin O.G. Highly reactive $\sigma$-organonickel complexes in electrocatalytic processes. Journal of Organometallic Chemistry. 2001;630(2) 185-192. 
[55] Yakhvarov D.G., Budnikova Yu H., Tazeev D.I., Sinyashin O.G. The influence of the sacrificial anode nature on the mechanism of electrochemical arylation and alkylation of white phosphorus. Russian Chemical Bulletin. 2002;51(11) 2059-2064. 